\title{
O APOIO DA TECNOLOGIA NA PRODUÇÃO TEXTUAL
}

\section{THE TECH SUPPORT IN TEXTUAL PRODUCTION}

\author{
Eliseo Berni Reategui ${ }^{1}$, Patrícia Campelo² ${ }^{2}$ Simone de Oliveira ${ }^{3}$ \\ ${ }^{1}$ Professor do Programa de Pós-Graduação em Informática na Educação - Universidade \\ Federal do Rio Grande do Sul (UFRGS) \\ ${ }^{2}$ Professora do Instituto de Letras - Universidade Federal do Rio Grande do Sul \\ (UFRGS) \\ ${ }^{3}$ Doutoranda do Programa de Pós-Graduação em Informática na Educação - \\ Universidade Federal do Rio Grande do Sul (UFRGS) \\ eliseo.reategui@ufrgs.br, patricia.campelo@ufrgs.br, simone.oliveiraprofe@gmail.com
}

\begin{abstract}
Resumo: Este artigo apresenta as dificuldades que os acadêmicos encontram para escrever textos científicos em consonância com os critérios de análise textual. O objetivo foi investigar como uma ferramenta de mineração de texto, capaz de organizálo graficamente, pode apoiar o processo de construção da escrita acadêmica para qualificá-la na dimensão da coerência. Foram escolhidas as abordagens qualitativa e quantitativa, com base em técnicas de coleta de dados como questionários, entrevistas e relatórios. Para analisar os dados foram empregadas estatísticas, análise de conteúdo e triangulação. Os resultados da pesquisa permitiram verificar que a ferramenta auxiliou os professores na avaliação das produções dos alunos, quanto a coerência.
\end{abstract}

Palavras-chave: Produção Textual. Critérios de Análise. Tecnologias Digitais. Sobek.

Abstract: This paper presents the difficulties that the students have to write scientific texts in line with the criteria for textual analysis. The main goal of this research has been to investigate how a text mining tool can help students organize their academic writing process, considering mainly the aspect of coherence. Qualitative and quantitative procedures were chosen as a research approach, based on the use of questionnaires, interviews and reports. Basic statistical analysis, content analysis and triangulation analysis were carried out. Results showed that the text mining tool has been able to help teachers evaluate students' writings based on coherence.

Keywords: Text Production. Analysis Criteria. Digital Technologies. Sobek.

\section{Introdução}

No ensino superior a produção textual é uma prática rotineira comum e exigida por todos os cursos da graduação ou pós-graduação, o que pode variar é a escala de exigência de quantidade ou qualidade da escrita. No entanto, ela acompanha o acadêmico do ingresso até o término do seu curso. Assim, o aluno produz uma grande diversidade de textos, desde resumos simples, resenhas, fichamentos até artigos científicos para publicação, relatórios técnicos e monografias, no nível de complexidade que cada etapa, disciplina ou estágio, exigirá. Jenner (2003) destaca 
ainda a necessidade de os indivíduos serem capazes de utilizar a linguagem oral e escrita para demonstrar sua compreensão do mundo em nossa sociedade contemporânea. A partir desta realidade descrita, o objetivo da pesquisa foi investigar como uma ferramenta digital capaz de representar um texto graficamente pode apoiar o estudante no processo de construção da escrita acadêmica para qualificá-la na dimensão da coerência, a partir de critérios de análise textual de Charolles (1995).

$\mathrm{O}$ uso de representações gráficas para apoio às atividades de leitura e produção textual tem sido objeto de estudo de muitos pesquisadores. Marzano, Pickering e Pollock (2001), por exemplo, discutem a importância do uso de representações não linguísticas para auxiliar os estudantes a compreender materiais escritos. Hyerle (2009) buscou demonstrar como diferentes tipos de ferramentas visuais, chamados de organizadores gráficos, podem auxiliar estudantes e professores a representar informações e melhor se comunicar. $\mathrm{O}$ emprego destes organizadores gráficos e outras atividades de pré-escrita também demonstrou ser efetivo, por exemplo, para auxiliar os aprendizes a segmentar o tópico sobre o qual devem trabalhar ajudando-os a melhor estruturar sua escrita (Beissner, Jonassen, e Grabowski, 1994). Neste sentido, Rudell (2001) enfatiza a importância de prover ao estudante ferramentas que lhe permitam ilustrar sua construção e organização do conhecimento, oportunizando que expressem visualmente ideias importantes e como estas podem se conectar.

$\mathrm{O}$ artigo inicia apresentando uma discussão introdutória referente à produção textual e critérios de análise textual. Em seguida, são apresentadas as contribuições das tecnologias digitais para qualificar o processo de produção textual. Logo é descrito, um estudo sobre o emprego de uma ferramenta de mineração de texto para apoio ao processo de escrita acadêmica, no qual participaram 50 acadêmicos de uma instituição superior no sul do país. Os resultados da pesquisa são apresentados e discutidos, buscando apontar as principais contribuições do trabalho.

\section{Critérios de Análise Textual}

Marcuschi e Xavier (2005) apontam que a produção textual se assemelha a um jogo no quais, antes de iniciar, têm de conhecer algumas regras e o espaço onde vai acontecer. Deste modo, além de terem clareza sobre o assunto sobre o qual vão discorrer, também é importante que os estudantes conheçam alguns critérios de análise textual. $\mathrm{O}$ foco desta pesquisa está na análise da coerência das produções acadêmicas, como proposta por Charolles (1978), a partir de quatro metarregras:

Repetição: referente à necessidade de realizar retomadas de elementos principais no decorrer da apresentação do texto, ou seja, propõe uma unidade entre os elementos. Um texto que ao longo da sua construção apresenta diferentes assuntos sem um ponto comum explícito, não tem continuidade.

Progressão: o texto deve retomar os conceitos principais, mas não se limitar a isto. Ele necessita evoluir, apresentar novas informações e relacioná-las aos elementos já mencionados anteriormente. Acréscimos semânticos demostram a progressão textual.

Não-contradição: um texto precisa apresentar princípios lógicos elementares, por exemplo, não poderá afirmar X e depois o contrário de X. As ideias apresentadas não podem se contradizer, devem responder ao objetivo do texto e se relacionar, mostrando-se compatíveis. 
Relação: um texto coerente e articulado apresenta relações e conexões estabelecidas claramente entre a ideia principal e as secundárias.

A próxima seção apresenta algumas tecnologias digitais que podem ser utilizadas como ferramentas no processo de elaboração textual.

\section{Tecnologias Digitais e a Produção Textual}

Neste artigo, são sugeridas algumas ferramentas para apoiar o aluno na produção e análise de seus textos. Conforme o nível de desenvolvimento do aluno, ele poderá ter que produzir textos de maior ou menor complexidade. Por isso, ferramentas que lhe auxiliem a analisar suas produções podem facilitar esse processo. A partir desse panorama, foram elencadas algumas sugestões, entre elas:

Textalyser: é uma ferramenta gratuita de análise de texto online. Ela apresenta estatísticas detalhadas, indicada para traduções ou para identificar o assunto sobre o qual trata o texto. Analisa grupo de palavras, apresenta a ideia principal e a proeminência da palavra por meio de tabelas e quadro-resumos.

Wordcounter: é uma ferramenta gratuita e online que conta as palavras do texto. Também apresenta as 10 principais palavras-chave e sua densidade do texto. Permite verificar o excesso de uso de algumas palavras e a distribuição correta das principais palavras no texto, sendo apresentada por meio de tabelas.

Tagcrowd, Wordle e Tagxedo: são ferramentas gratuitas e online que criam uma nuvem de palavras a partir de qualquer texto para visualizar a frequência dos termos utilizados. É possível parametrizar algumas características, como por exemplo, número de palavras que deve conter a nuvem, número de frequência das palavraschave do texto, a língua do texto e as palavras que se quer excluir da nuvem.

LinguaKit: possui ferramentas linguísticas, como sumarizador, corretor, tradutor e conjugador verbal. Possui análise linguística por meio da frequência de palavras, identificação da palavra-chave, etiquetador morfossintático e analisador sintático. Possibilita a análise textual por meio do analisador de sentimento, identificador de idioma, extrator de palavras-chave, extrator de multipalavra e extrator de conceitos. Todos os resultados são apresentados por meio de tabelas e relatórios.

Intex Mining: é uma ferramenta para minerar o texto ou preparar o texto. Apresenta a identificação dos conceitos e estatísticas sobre o uso destes conceitos, a frequência com que o conceito aparece e as associações entre eles. Também apresenta comparação entre textos, palavras comuns e exclusivas por meio de quadros e tabelas.

Sobek: é um software de mineração de texto que permite a análise e identificação de informações relevantes. Sobek foi desenvolvido fomo uma ferramenta educacional e está sendo utilizada em tarefas como apoio a atividades de leitura, resumo e interpretação de textos. Ao submeter um texto no Sobek, ele sistematiza o resultado no formato de um grafo, como um mapa conceitual, apresentando os principais conceitos e suas associações por meio de uma representação gráfica.

A partir da análise dessas ferramentas pode-se perceber que algumas apresentam a ideia principal do texto, realizam a contagem de palavras, e organizam seus resultados por meio de tabelas, listas ou relatórios. Na pesquisa apresentada neste artigo, foi escolhida a ferramenta Sobek, por ser de fácil utilização e apresentar uma representação visual de um texto na qual são enfatizados seus conceitos mais relevantes, bem como, o relacionamento entre eles. Entende-se que tais características, presentes na ferramenta Sobek, podem facilitar seu emprego na identificação de 
problemas de coerência, como proposto nesta pesquisa. A próxima seção apresenta o estudo desenvolvido a partir do uso da ferramenta Sobek.

\section{Métodos}

Com intuito de responder a situação-problema apresentada, referente às dificuldades na produção da escrita acadêmica relatada por uma parcela significativa de alunos, essa pesquisa foi aplicada numa instituição de ensino superior, na disciplina de Metodologia da Pesquisa Científica, com 50 acadêmicos.

As atividades ocorreram com o apoio da professora da disciplina e com cinco outros alunos tutores, que fazem parte de um grupo de pesquisa referente a qualificação da escrita acadêmica. Diante da experiência da professora relatada quanto às dificuldades de escrita, essa pesquisa começou a sistematizar a investigação, iniciando por um levantamento de perfil. Entre os participantes, 34 acadêmicos $(68 \%)$ tinham entre 17 e 25 anos, muitos destes saindo recentemente do ensino médio, 13 acadêmicos $(27 \%)$ estavam no $3^{\circ}$ semestre da faculdade e 9 acadêmicos (18\%) encontravam-se no $5^{\circ}$ semestre. Do total de participantes, 32 alunos (64\%) já haviam cursado a disciplina de Português Instrumental. Mesmo assim, diziam apresentar dificuldades no processo de produção textual, como se pode perceber na figura 1:

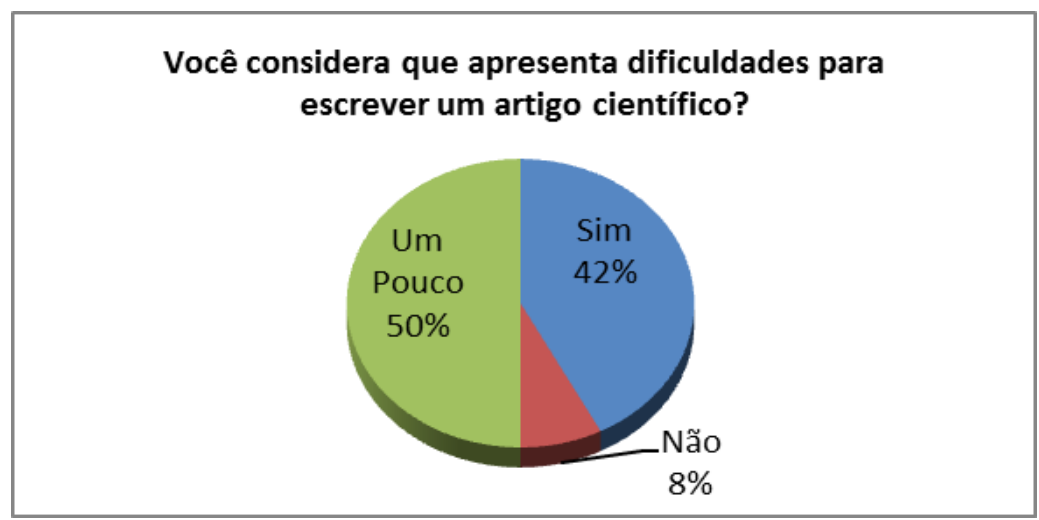

Figura 1 - Dificuldades para escrever Fonte: Autor

A professora da disciplina de Metodologia da Pesquisa Científica juntamente com o apoio de quatro alunos tutores, realizou a análise dos textos produzidos pelos estudantes por meio das seguintes etapas: (a) identificação do objetivo geral do texto; (b) geração do grafo de todo o texto com a ferramenta Sobek; (c) geração do grafo referente a cada um dos capítulos do texto; (e) análise dos critérios que tornam um texto coerente a partir das principais características de cada categoria, sendo quantificados por meio de uma tabela de registros. O resultado desta análise é apresentado nas próximas subseções.

\subsection{Critério de Repetição}

O critério de repetição propõe que o texto apresente os conceitos principais com um grau de repetição para relacionar ideias, associá-las e evoluir em seu desenvolvimento e fechamento. Para tal, o texto deve incluir elementos que induzam a apresentação da ideia principal de forma homogênea, retomando conceitos e trazendo continuidade semântica para a escrita. No exemplo apresentado na figura 2, o aluno 
escreveu sobre a influência que a autoestima pode ter no sucesso pessoal e profissional das pessoas. Como se podem observar, estes conceitos aparecem tanto no grafo geral do artigo, como no grafo da Introdução.

A análise dos textos dos estudantes pelo professor da disciplina permitiu verificar que 24 textos (48\%) apresentaram continuidade entre a definição do conceito principal e a apresentação dos demais conceitos. A extração dos grafos dos textos possibilitou confirmar esta informação, como no exemplo ilustrado na figura 2 . No exemplo, observam-se os termos 'Autoestima, pessoal e profissional' na extração de conceitos realizada para todo o texto (grafo geral). Na porção direita da mesma imagem, para a mineração apenas da Introdução do texto, um conjunto de termos muito semelhante pode ser observado 'Autoestima, sucesso pessoal e profissional'. A identificação dos termos nos grafos obtidos para o texto completo e apenas para a introdução do trabalho permite verificar que houve certo nível de repetição na utilização destes conceitos ao longo do texto.

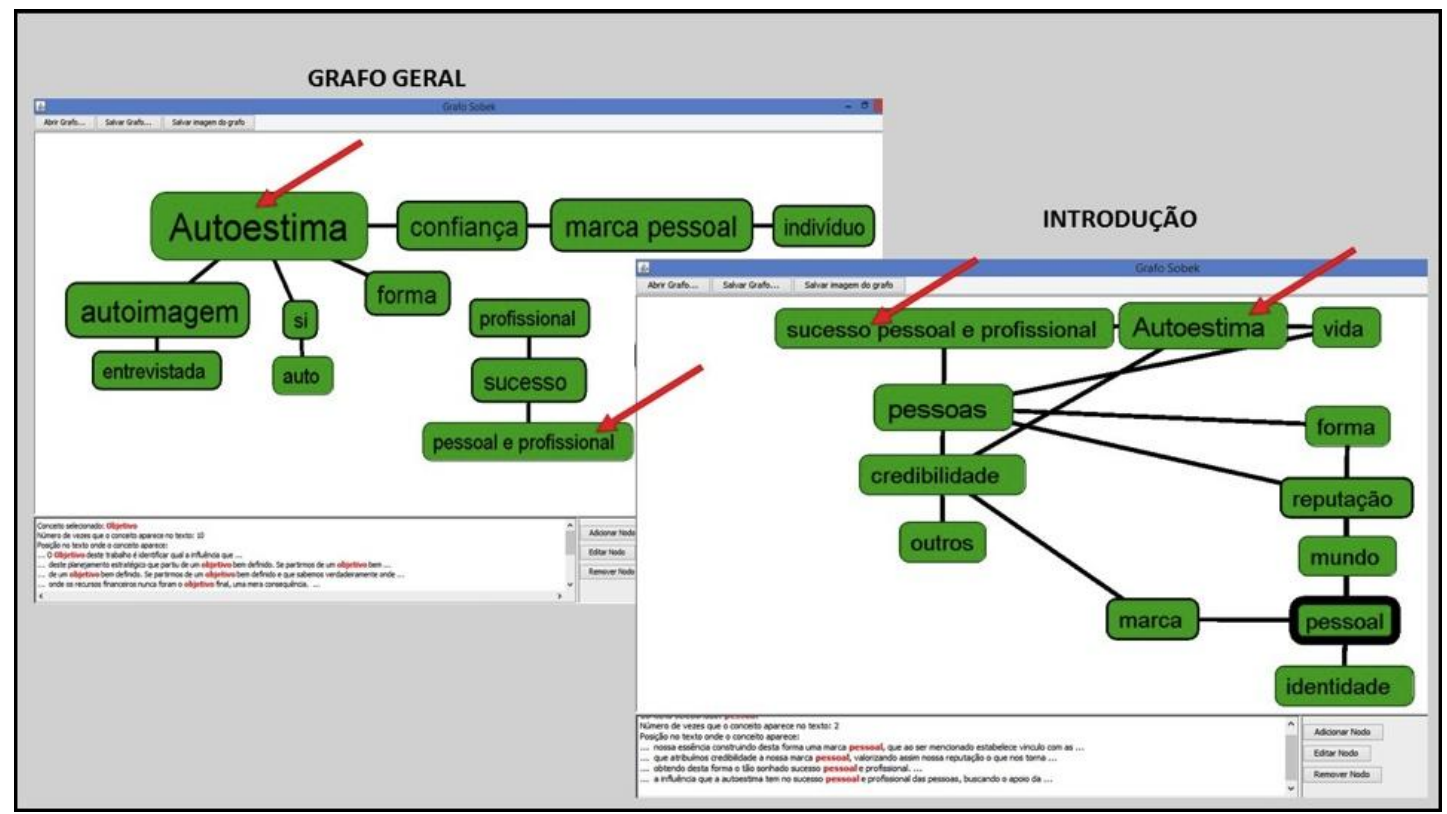

Figura 2 - Grafo Geral do Texto e Grafo da Introdução Fonte: Autor

Conforme relato da professora da disciplina, essa situação em que a repetição do conceito principal do texto, está presente em todos os grafos gerados dos capítulos do artigo, é excelente, pois sugere que esse texto seja integrado, ou seja, coerente na perspectiva do critério de repetição. Essa realidade de falta de repetição semântica necessária para a construção do texto foi relatada por uma das tutoras que auxiliou na avaliação dos textos apoiada pelos grafos da ferramenta Sobek: "Eu verifiquei diferenças nos grafos gerados para partes do mesmo artigo. As palavras muitas vezes não se repetiam, em alguns grafos, e também houve diferença na quantidade de palavras geradas [...] Em alguns trabalhos, houve a percepção de conceitos que não apresentavam conexões". (Tutora A). No relato de outra tutora, é possível verificar a mesma situação: "Encontrei diferenças nos grafos gerados das partes do texto, [em] alguns as palavras-chave, ou mais importantes, não eram iguais, não se repetiam nos grafos seguintes". (Tutora B). Na fala das tutoras é perceptível como à ferramenta pode auxiliar na avaliação das produções dos alunos, quanto à primeira metarregra relacionada à repetição. A avaliação deste critério pode auxiliar na qualificação da 
escrita dos estudantes, tornando seus textos mais coerentes a partir de sua construção envolvendo os elementos lógicos e necessários da repetição.

\subsection{Critério de Progressão}

A segunda metarregra exige que o texto não se restrinja em si mesmo, mas que proponha elementos que desenvolvam ideias e conceitos expostos. Sendo assim, é necessário que o texto retome os seus conceitos principais, contudo sem limitar-se unicamente a esse processo de repetição. Novos conhecimentos devem ser introduzidos e associados aos conceitos anteriores, esse processo é conhecido como acréscimo semântico.

Dos 50 textos submetidos para análise por meio do Sobek, 20 deles (40\%) apresentaram progressão semântica, mesmo que pequena. A figura 3 mostra um exemplo do texto de um aluno cujo objetivo geral era apresentar as estratégias de marketing aplicadas ao mercado de suco de uva orgânico em uma vinícola no sul do país. A professora da disciplina e a tutora que avaliaram o texto consideraram que ele atendeu a metarregra da progressão, o que pode ser confirmado pelos grafos obtidos a partir da mineração de duas partes do texto pela ferramenta Sobek (Referencial Teórico e Considerações Finais). A professora ressaltou que justamente, nas considerações finais, onde o texto deveria apontar o alcance dos resultados, a evolução e as contribuições, o grafo conseguiu enfatizar essa característica.

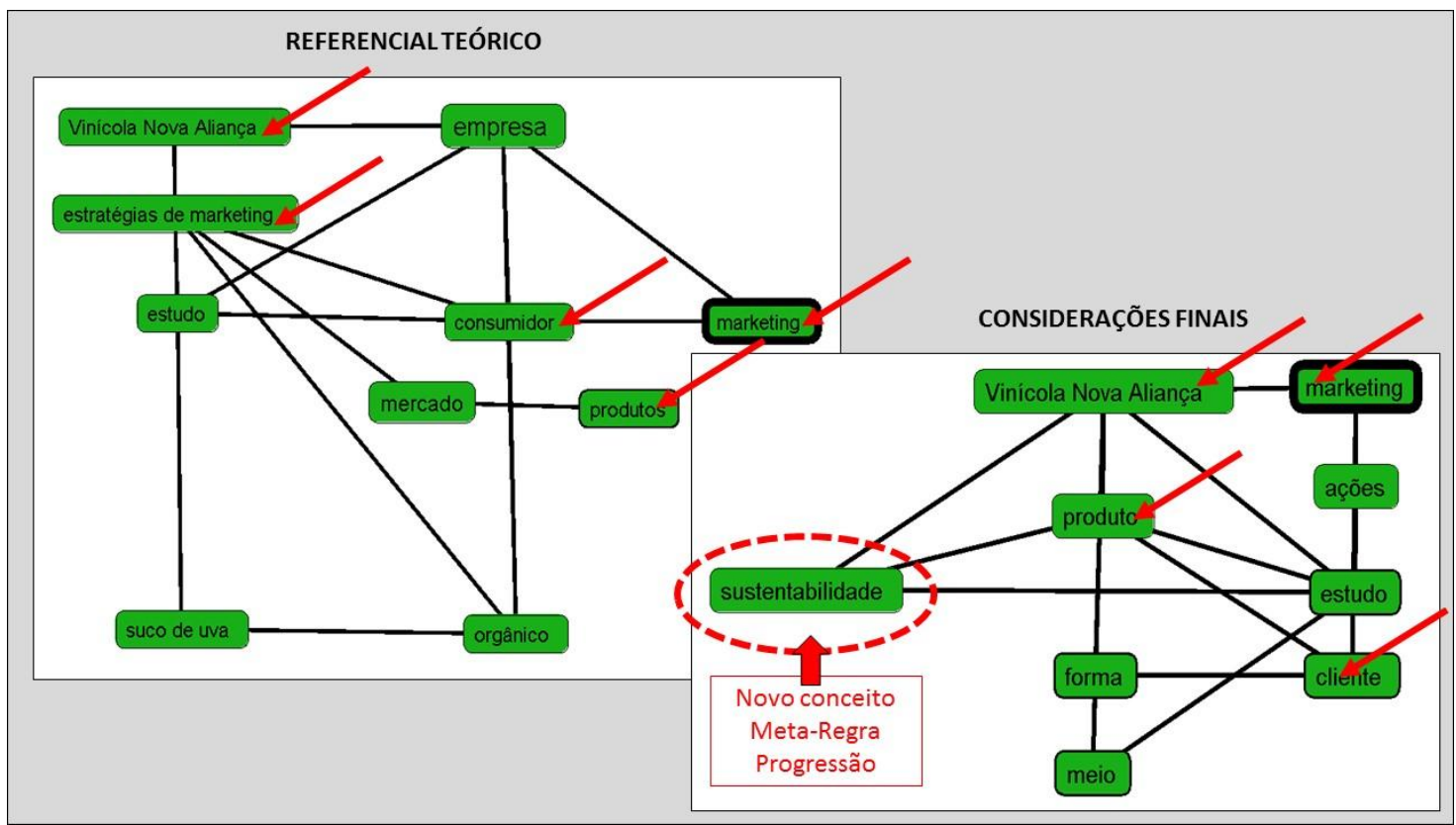

Figura 3 - Metarregra Progressão

Fonte: Autor

Observa-se na imagem que um novo conceito surge nas considerações finais, o conceito de sustentabilidade, sendo este associado a outros conceitos presentes em seções anteriores do texto, tais como 'marketing, produto, consumidor', e o nome da empresa para a qual o estudo estava sendo desenvolvido. A introdução do novo conceito e sua associação a ideais anteriores atende a metarregra relacionada à progressão. 
A aluna tutora que avaliou o texto relatou que: "Ao submeter esse texto no Sobek percebi que ele se apresentava numa sequência lógica, que cada um dos grafos gerados das partes do texto, reforçava o objetivo do artigo, mas chamou minha atenção que a partir da análise dos resultados e das considerações finais, o aluno introduziu um novo conceito que não havia anteriormente, nesse caso, específico, o conceito de sustentabilidade". (Tutor A).

\subsection{Critério de Não-Contradição}

A terceira metarregra, a não-contradição, espera que o texto não se contradiga, seja coerente e compatível com seus conceitos principais. Em textos mais complexos, uma contradição intencional pode ocorrer para levar o leitor a refletir. Contudo, na escrita acadêmica, produzida pelos estudantes, este tipo de prática não é muito frequente. No experimento realizado, 40 dos textos submetidos (80\%) não apresentaram evidências significativas do critério de não-contradição. A fala de um tutor confirma esta característica dos textos: "[...] os trabalhos apresentavam uma sequência, uma ideia principal do que estava descrito no artigo, sem contradições gritantes. Inclusive um dos textos apresenta uma pesquisa do aluno, em que ele usou o Sobek para buscar contradições nas falas dos entrevistados. Essa experiência foi muito interessante". (Tutor C).

Pode-se perceber esse critério sendo respondido por meio da figura 4, utilizada para exemplificar essa prática. $\mathrm{O}$ texto do acadêmico representado na figura trata de uma pesquisa referente à satisfação do aluno com a sua instituição de ensino, questionando-o também se ele daria continuidade aos estudos nessa mesma instituição. Para isso, foi realizada uma coleta de dados específica, mas o recorte apresentado aqui para exemplificar o critério de não-contradição, refere-se ao quesito 'Retenção'. O aluno aplicou a técnica de grupo focal para três grupos diferentes e buscou a existência ou não de contradições nas falas que foram gravadas, transcritas e depois submetidas ao Sobek. A pergunta motivadora desses grafos foi: "- Você recomendaria essa IES para outras pessoas?" 
Questão sobre retenção - respostas por grupo focal

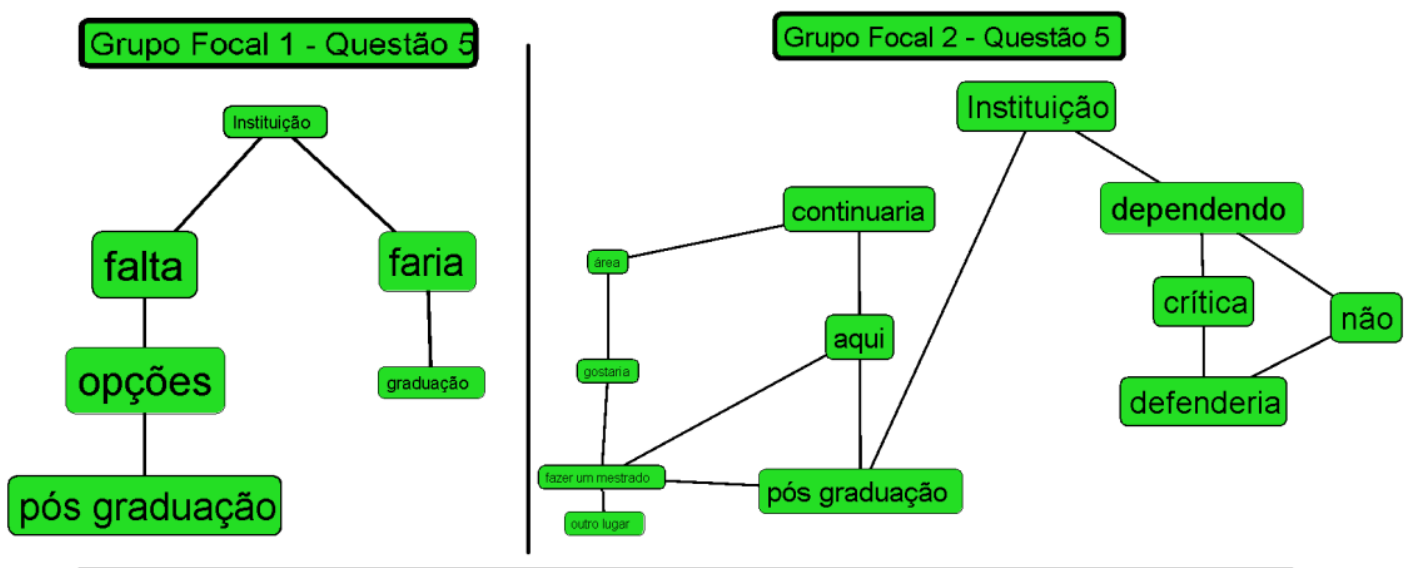

Grupo Focal 3 - Questão 5

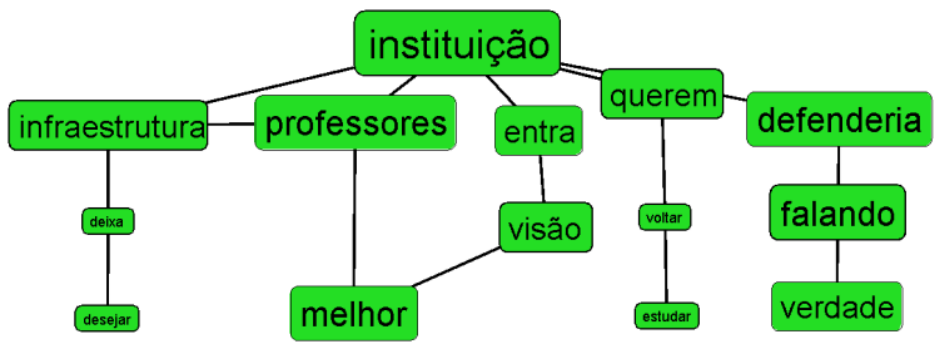

Figura 4 - Metarregra Não-Contradição

Fonte: Autor

É interessante ressaltar que, quando se trata da metarregra não-contradição, não se pode aplicar apenas as não-contradições conceituais, ou de falas de entrevistas. Deve-se também avaliar elementos como o tempo, as inferências e outras informações que os grafos extraídos pelo Sobek podem destacar.

\subsection{Critério de Relação}

A quarta metarregra, chamada de relação, compõe e finaliza o conjunto de critérios relacionado à coerência textual. Para cumprir essa meta, o texto deve apresentar seus conceitos principais e secundários formalizados, relacionados e associados de modo claro. Para que o texto seja aceito como coerente, a partir dessa metarregra, ele precisa ter conceitos congruentes, conectados de forma a dar um sentido harmonioso ao que ser relatar. Na pesquisa realizada 24 textos apresentaram esta característica. Nos demais textos, ao analisá-los com auxílio da ferramenta Sobek, foi possível observar que conceitos importantes apareciam muitas vezes desconectados do restante do grafo, como ilustrado na figura 5. Neste exemplo, é possível perceber como os termos PCDs no mercado e pessoas com deficiência PCD aparecem desconectados do restante do grafo. 


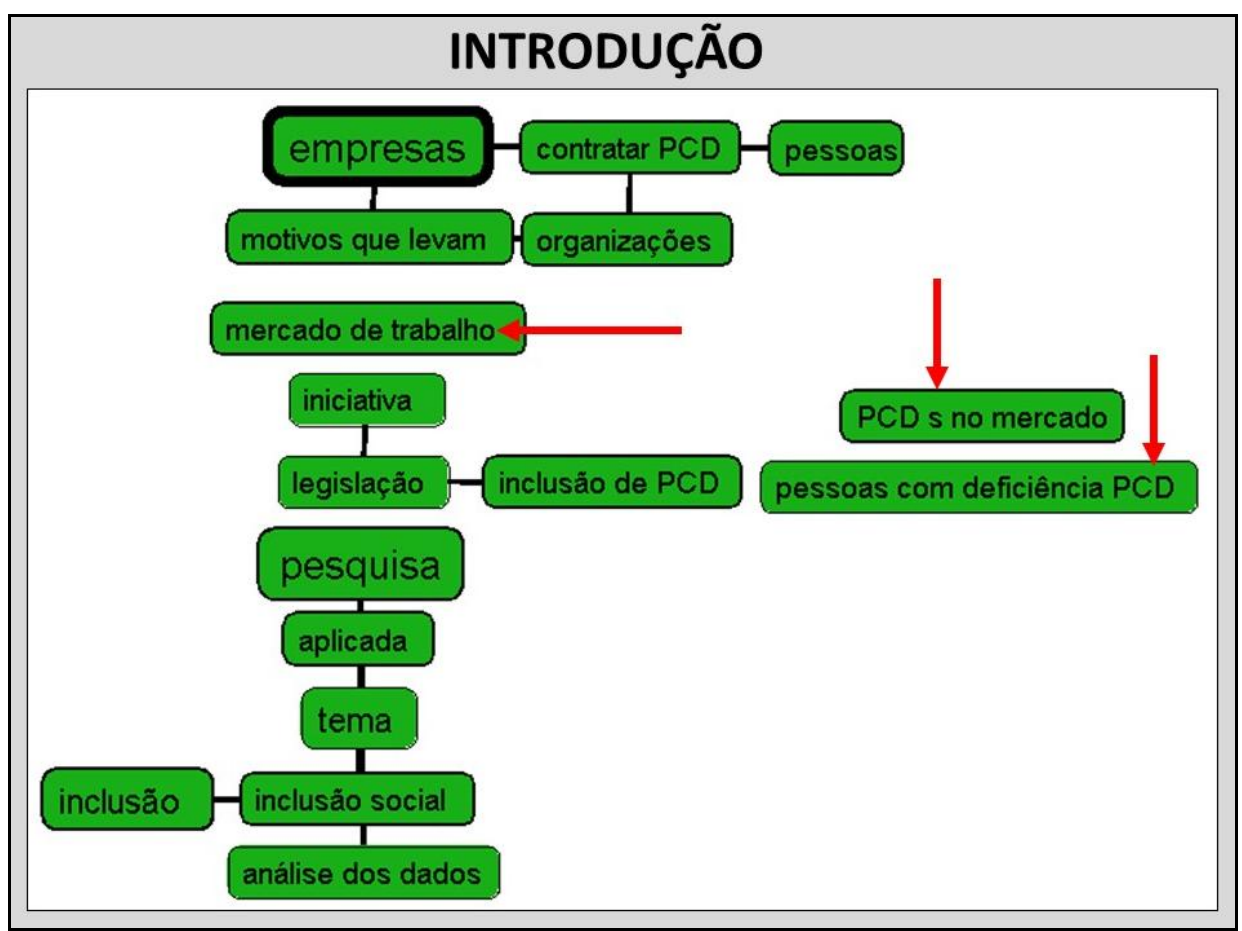

Figura 5 - Metarregra Relação

Fonte: Autor

Essas quatro metarregras apresentadas fazem parte de um processo de análise linguística e pragmática que podem contribuir na análise da coerência de textos acadêmicos. Aqui, utilizou-se a ferramenta para auxiliar o trabalho dos professores e tutores. Contudo, seria possível empregar a ferramenta diretamente com os alunos para ajudá-los na organização e revisão de suas próprias produções textuais, o que será realizado em futuras etapas desta pesquisa.

A tabela 1 apresenta uma visão geral da análise dos textos dos estudantes quanto às quatro metarregras associadas à coerência.

Tabela 1: Visão Geral das Categorias Analisadas

\begin{tabular}{|l|l|l|}
\hline \multicolumn{1}{|c|}{ Categoria } & \multicolumn{1}{|c|}{$\begin{array}{c}\text { Número de trabalhos } \\
\text { analisados }\end{array}$} & Média em Percentual \\
\hline \multicolumn{3}{|c|}{ Critérios de análise da Coerência Textual } \\
\hline Repetição & 24 & $48 \%$ \\
\hline Progressão & 20 & $40 \%$ \\
\hline Não-Contradição & 40 & $80 \%$ \\
\hline Relação & 22 & $44 \%$ \\
\hline
\end{tabular}

Numa perspectiva de conhecer a satisfação subjetiva dos tutores participantes da pesquisa em relação ao uso da ferramenta Sobek para apoio à avaliação dos textos, foram aplicadas algumas entrevistas. Conforme relato de uma das tutoras participantes, "[...] realizando este trabalho, foi possível ver o quão importante pode ser o uso de um software para os acadêmicos. Não foi diferente com o Sobek, o mesmo auxilia muito para o aperfeiçoamento dos trabalhos, destacando também a importância de identificar os conceitos principais e secundários, assim como, as suas relações que constam no grafo de forma correta". (Tutora D). Já o Tutor E, relatou: "Gostei muito de fazer parte desse trabalho, porque acredito que o Sobek possa auxiliar os alunos na hora de 
escrever, de se corrigir e melhorar como escritor acadêmico, pois com as análises dos grafos podemos enxergar os nossos erros e corrigi-los para esse ou para os próximos trabalhos".

$\mathrm{Na}$ pesquisa desenvolvida, foi possível observar que muitas dificuldades dos alunos no processo de escrever, se encontra nos critérios de repetição e progressão, o que estabelece a continuidade, as conexões dos conceitos anteriores com novos conceitos, isso se dá a partir de leituras consistentes e a prática da própria escrita. Os resultados alcançados mostraram o potencial da ferramenta Sobek para identificar problemas relacionados a estes critérios.

\section{Considerações Finais}

Quando se trata de pesquisar métodos ou ferramentas que possam auxiliar o processo de produção textual é possível encontrar um universo de teorias ou ferramentas que de alguma forma apresentam possibilidades de qualificar o texto a ser construído. Na pesquisa desenvolvida, foi avaliada uma metodologia de submissão de artigos dos acadêmicos à ferramenta de mineração textual Sobek, e subsequente interpretação dos grafos obtidos a partir das quatro metarregras relacionadas à coerência textual. Os resultados dos experimentos mostraram o potencial da ferramenta Sobek para facilitar a análise da escrita acadêmica, principalmente em critérios relacionados à coerência.

Para pesquisas futuras, julga-se importante acrescentar o critério de coesão às análises realizadas, sendo este composto por doze metarregras. Também seria relevante pensar na estrutura de funcionamento do Sobek para possibilitar que o acadêmico pudesse inserir suas palavras-chave do texto e a ferramenta apresentasse o nível de coerência por meio das metarregras de repetição, progressão e relação. Ao avançar nesse campo de pesquisa, entende-se que estas investigações devam favorecer o processo de qualificação da escrita acadêmica. Ao minimizar dificuldades e potencializar oportunidades aos alunos de conhecer e experimentar novas tecnologias digitais, oportunizamos práticas pedagógicas que permitem a apropriação do saber por meio da ação, reflexão e ação.

\section{Referências}

BEAUGRANDE, Robert Alain, DRESSLER, Wolfgang Ulrich. Introduction to text linguistics. London: Longman, 1981.

BEISSNER, K., JONASSEN, D.H. and Grabowski, B.L, "Using and selecting graphic techniques to acquire structural knowledge", Performance Improvement Quarterly, 7(3-4). 20-38. 1994.

CHAROLLES, Michel. Introduction aux problèmes de la cohérence des textes [Approche théorique et étude des pratiques pédagogiques]. Langue française, v. 38, 1978. Enseignement du récit et cohérence du texte. pp. 7-41. Disponível no endereço eletrônico: <http://www.persee.fr/doc/lfr_0023-8368_1978_num_38_1_6117>. Acessado no dia 21/09/2015. 
CHAROLLES, Michel. Cohesion, coherence et pertinence du discours. Travaux de Linguistique, De Boeck e Larcier, Duculot, 1995, pp.125-151. Disponível no endereço eletrônico: <https://halshs.archives-ouvertes.fr/halshs-00334043/document> Acessado dia 21/09/2015.

HYERLE, David. Visual tools for transforming information into knowledge. Corwin Press, Thousand Oaks, 2009.

JENNER, Jan. A bridge to reading and writing literacy: developing oral language skills in young children. Pacific Educator, v. 2, n. 1, 2003.

MARCUSCHI, Luiz Antônio; XAVIER, Antônio Carlos. Hipertexto e gêneros digitais: novas formas de construção do sentido. 2 ed. Rio de Janeiro: Lucerna, 2005.

MARZANO, Robert; PICKERING, Debra; POLLOCK, Jane. Classroom instruction that works: Research-Based Strategies for Increasing Student Achievement. Association for Supervision and Curriculum Development, Alexandria, 2001.

RUDDELL, Martha Rapp. Teaching content reading and writing. John Wiley \& Sons, New York, 2001. 